\title{
Anemia and its risk determinants among young adults: A university-based study of Bangladesh
}

\author{
Mst. Sabrina Moonajilin , Md Estiar Rahman ${ }^{1, *}$, Quazi Maksudur Rahman², Abid Hasan Khan²
}

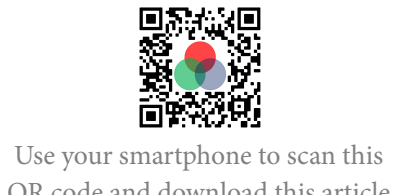

QR code and download this article
${ }^{1}$ Department of Public Health and Informatics, Jahangirnagar university, Savar, Dhaka-1342 Bangladesh

${ }^{2}$ Department of Public Health and Informatics, Jahangirnagar university, Savar, Dhaka-1342, Bangladesh

\section{Correspondence}

Md Estiar Rahman, Department of Public Health and Informatics, Jahangirnagar university, Savar, Dhaka-1342 Bangladesh

Email: estiarju@gmail.com

History

- Received: 2020-01-17

- Accepted: 2020-02-09

- Published: 2020-3-20

DOI : estiarju@gmail.com

\section{Check for updates}

\section{Copyright}

(-) Biomedpress. This is an openaccess article distributed under the terms of the Creative Commons Attribution 4.0 International license.

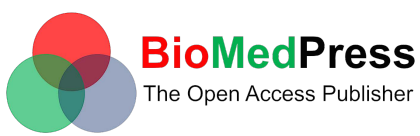

\begin{abstract}
Objectives: This study aimed to determine the prevalence and risk determinants of anemia among young adults (university students) in Bangladesh. Methods: A total of 150 students aged $\geq 18$ years were randomly selected from Jahangirnagar University, Savar, Bangladesh. Data on students' socio-demographic information, hygiene practices, and dietary intakes were collected through a self-administered questionnaire. A blood sample was taken from the students to estimate the hemoglobin level. The students having hemoglobin levels below $13.0 \mathrm{gm} / \mathrm{dl}$ for males and 12.0 $\mathrm{gm} / \mathrm{dl}$ for females were considered anemic. All categorical variables were compared using the chisquare test and regression analysis. Results: The mean ( \pm SD) age of the total students was 21.44 $( \pm 1.64)$ years. Among 150 students, $46.7 \%(n=70)$ were males and $53.3 \%(n=80)$ were females. Of these $(n=150), 22 \%(n=33)$ were diagnosed as having any form of anemia. Out of 33 anemic students, $70 \%(n=26)$ had mild anemia, $5 \%(n=7)$ had moderate anemia and none of the students found to be severely anemic. Among the socio-demographic characteristics, gender and monthly family income had a significant effect on anemia $(p<0.05)$. Regarding hygiene practices, handwashing with soap before the meal and after toileting, and regular basis nail cutting were significantly associated with a lower prevalence of anemia $(p<0.05)$. Regarding dietary habits, daily breakfast intake, frequent consumption ( $\geq 3$ times/week) of fruits, green leafy vegetables and animal products (meat, fish, and egg) were significantly associated with a lower prevalence of anemia $(p<0.05)$. Conclusion: Proper health education to increase knowledge about anemia, benefits of healthy dietary habits and the importance of hygiene practice can be implemented among the students.
\end{abstract}

Key words: Anemia, Dietary habits, Hemoglobin level, Hygiene practices, University students

\section{INTRODUCTION}

Anemia can be defined as a condition in which the number of red blood cells or $\mathrm{Hb}$ level falls below an established cut-off value, consequently impairing the capacity of the blood to transport oxygen to the cells ${ }^{1}$. Anemia is a global public health problem that affects about 2.3 billion people worldwide ${ }^{2}$. In developing countries, it has become more of a concern where the incidence and severity of anemia are very high compared to developed countries. An estimated 43\% population had been reported to be anemic in developing countries ${ }^{3}$. Young people are particularly susceptible because of their rapid growth and associated high iron requirements ${ }^{4}$. Previous studies around the globe reported the prevalence of anemia among young adults ${ }^{5,6}$. A Bangladeshi study conducted in the Noakhali region reported $55.3 \%$ of adults university students to be anemic ${ }^{7}$. Around $30 \%$ of university students were reported to be anemic in the Hodeida Province of Yemen ${ }^{8}$. A similar study from South India showed that $43 \%$ of university students had anemia
- The magnitude of anemia has significant adverse health and economic consequences. Studies reported that anemia is associated with reduced labor productivity in adults and combining the effect of anemia on cognition, total economic loss was estimated to be US\$ 16.78 per capita or $4.05 \%$ of the GDP ${ }^{9,10}$. Despite the high burden and increasing trend of anemia, both in terms of prevalence and economic impact, there is a limited body of knowledge on anemia among young adults and this population has long been neglected and is an overlooked area of research as compared to children and women.

Dietary deficiency and poor hygiene practices play a major role in the causation of anemia ${ }^{11,12}$. Inadequate dietary intake and poor hygiene practice are important public health issues among university students as they are experiencing the transition into university life. Living university hostels away from home badly influence their dietary intakes and hygiene practices. Previous studies have shown that university students tended to skip meals and often failed 
to meet the recommended intakes for fruits and vegetables $^{8,13}$. Personal hygiene is particularly important among university students because they spend most of their time in public places or universities in proximity to others. Poor hygiene practices favor parasite infection which in turn may result in anemia ${ }^{14}$.

Bangladesh is a heavily densely populated country in South Asia. It has very high population growth, widespread poverty, rising food prices, lack of access to services like education and health care. According to the World Bank, almost 1 in 4 Bangladeshis (24.3 percent of the population) live in poverty ${ }^{15}$. In Bangladesh, anemia has long been considered as a serious public health problem. Previous studies have shown that the prevalence of anemia in Bangladesh varies between $39.9 \%$ and $51.9 \%$ among women and children, respectively ${ }^{16,17}$. Most of the previous studies on anemia in Bangladesh were conducted on children and women. However, there is a relative lack of information about the prevalence and risk factors of anemia among young adults, particularly among adult populations at the university stage. Therefore, the present study aimed to determine the prevalence and risk determinants of anemia among adult students of a major university in Bangladesh.

\section{MATERIALS AND METHODS}

\section{Participants and procedure}

This investigation involved a cross-sectional study conducted at Jahangirnagar University, Savar, Bangladesh. A simple random sampling technique was employed to recruit subjects for this study. A total of 150 young adult students were sampled from different disciplines of the university during September 2018 and February 2019. Only residential students aged 18 years or above were included. The students were invited to the Public Health and Informatics Department's laboratory of the university. Before participation, the aims and methods of the study were clearly defined to the students and written consent was taken from each participant. After taking consent, students were requested to complete a questionnaire and to provide a blood sample. The questionnaire included questions concerning students'socio-demographic information, hygiene practices, and dietary intakes. Participation was completely voluntary and the obtained data were kept as confidential.

\section{Measures}

\section{Socio-demographic information}

Data on socio-demographic characteristics including age, gender, university studying program and year, relationship status, monthly family income were gathered. Presence of self-reported in illness in the last 6 months, smoking habit and anti-helminthic drug intake of the students were also recorded.

\section{Hygiene practices}

To assess hygiene practice, four items were used. The four items included question concerning handwashing with soap before the meal, handwashing with soap after using the toilet, brushing teeth per day and cut nails regularly.

\section{Dietary intakes}

Dietary intake was assessed using a 7-days food frequency questionnaire (FFQ) and included breakfast intake, the frequency of consumption of fruits, green leafy vegetables, milk/dairy products, and animal products (meat, fish, and egg). The types of foods taken (fruits, vegetables, milk/dairy products, and animal products) were classified into the following: frequently ( $\geq 3$ times/week), infrequently $(<3$ times/week) and occasionally.

\section{Anemia screening}

Five $\mathrm{ml}$ of venous blood was taken under aseptic conditions from each student. The participant was allowed to leave the place after five minutes if they didn't report any problems such as pain, blood oozing or giddiness. Hematology analyzer (Mindray BC-3000 plus, China) was used to estimate the concentration of $\mathrm{Hb}$ in blood. Students with $\mathrm{Hb}$ levels lower than cutoff values were considered to be anemic if $\mathrm{Hb}<13.0$ $\mathrm{g} / \mathrm{dl}$ for male and $<12.0 \mathrm{~g} / \mathrm{dl}$ for female ${ }^{18}$. The severity of anemia was further graded as per WHO guidelines (SeeTable 1) ${ }^{1}$. We further observed RBC's morphology by a using light microscope (Model: XSZ107BN, China).

\section{Data analysis}

After the collection of data, it was checked for completeness or any discontinuation. The data were entered and analyzed using the statistical package for social sciences (SPSS), version 22. Frequency distribution tables and graphs were used to present the findings. All categorical variables were compared using the chi-square test and regression analysis. The association of variables was considered significant when the p-value was less than or equal to 0.05 . 
Table 1: Hemoglobin levels to diagnose anemia $(\mathbf{g} / \mathrm{dL})$

\begin{tabular}{lcccc}
\hline Individuals & Non-anemia & \multicolumn{3}{c}{ Anemia } \\
& & Mild & Moderate & Severe \\
Male (15 years of age and above) & 13 or higher & $11.0-12.9$ & $8.0-10.9$ & lower than 8.0 \\
$\begin{array}{l}\text { Female (15 years of age and } \\
\text { above) }\end{array}$ & 12 or higher & $11.0-11.9$ & $8.0-10.9$ & lower than 8.0 \\
\hline
\end{tabular}

\section{Ethical approval}

The present study was performed following the guidelines for medical research in the Helsinki Declaration, 1975. The study was approved by the institutional review broad of the Faculty of Biological Sciences, Jahangirnagar University. Informed written consent was provided by the participants before data collection. No incentive was offered to the participants for taking part in the study. Anonymity and confidentiality were ensured for all participants.

\section{RESULTS}

The socio-demographic characteristics of the students ( $\mathrm{n}=150)$ participated in the study are presented in Table 2. The participants' mean age was 21.44 ( \pm $1.64)$ years. Of these 150 , nearly $47 \%(n=70)$ were male and $53 \%(\mathrm{n}=80)$ were female. The majority of them $(66.7 \%)$ were enrolled in non-biology disciplines. $14.7 \%$ of the students were studying in $2^{\text {nd }}$ year, followed by $64.7 \%$ in $3^{\text {rd }}$ year and $20.6 \%$ were in $4^{\text {th }}$ year/Masters. Most of the students (90.7\%) were not married. Less than half of the participants' monthly family income $(40.7 \%)$ was in the range BDT 10,001-20,000. About $21 \%(n=32)$ participants reported that they had some sort of illness in the previous 6 months and the majority of participants (79.3 $\%$ ) were non-smokers (Table 2).

Among 150 adult students who were participating in the study, 33 (22.0\%) were diagnosed as having anemia, of whom $78.8 \%(n=26)$ were females and 21.2 $\%(\mathrm{n}=7)$ were males. Of these anemic students ( $\mathrm{n}$ = 33), $78.8 \%(\mathrm{n}=26)$ had mild anemia, $7(21.2 \%)$ had moderate anemia and none of the students were found to be severely anemic (Figure 1). By morphological examination of the RBCs, we observed that the students diagnosed to be mild anemic had normocytic ormochromic anemia and moderate anemic students had microcytic hypochromic anemia. The images of the RBCs of the mild and moderate anemic students are presented in Figure 2 and Figure 3, respectively. Among the socio-demographic variables examined, Chi-square analysis revealed significant association of anemia and socio-demographic factors: gender $(\chi 2$
$=11.014, \mathrm{p}<0.05)$ and monthly family income $(\chi 2$ $=8.091, \mathrm{p}<0.05)($ Table 2$)$.

Table 3 shows the hygiene practices and dietary intakes of the students. The study revealed that $48.7 \%$ $(\mathrm{n}=73)$ students washed their hands with soap before each meal, while $76.7 \%(n=115)$ washed their hands with soap after using the toilet. The percentages of the students brushing teeth twice per day and cutting nails regularly were $76.0 \%$ and $82.0 \%$, respectively. Regarding dietary intakes, regular breakfast intake was reported by $42.7 \%(n=64)$ students. Around thirty-one percent students $(n=47)$ consumed fruits frequently ( $\geq 3$ times/week) followed by infrequently ( $<3$ times/week) $56.7 \%(\mathrm{n}=85)$ and occasionally $12.0 \%(n=18)$. More than half of the students $(56 \%)$ reported that they consumed green leafy vegetables more than 3 times/week and more than two-third (71.3\%) consumed milk/dairy products more than 3 times/week. The majority, $63.3 \%$ (n =95) students consumed animal products (meat, fish, egg) more than 3 times/week (Table 3).

Depending on the analysis in the present study, a significant relationship between anemia and hygiene practices was demonstrated. The chi-square analysis showed that the prevalence of anemia was significantly lower among the students who maintained hygiene practices i.e., washed hand with soap before the meal and after using the toilet and regular basis nails cutting $(\mathrm{p}<0.05)$ (Table 2). Binary logistic regression analysis further revealed the significant predictors of lower prevalence of anemia: washing hand with soap before meal $(\mathrm{COR}=2.25,95 \% \mathrm{CI}=1.00-5.07$; $\mathrm{p}<$ 0.05), washing hand with soap after using the toilet $(\mathrm{COR}=2.81,95 \% \mathrm{CI}=1.21-6.49 ; \mathrm{p}<0.05)$ and cutting nail regularly $(\mathrm{COR}=2.56,95 \% \mathrm{CI}=1.04-6.31$; $\mathrm{p}<0.05$ ) (Table 4).

The relationship between anemia and dietary intakes was also statistically demonstrated in the present study. The chi-square analysis revealed that the prevalence of anemia was significantly higher among the students who skipped breakfast compared to those who did not $\left(27.9 \%\right.$ vs $\left.14.1 \%, \chi^{2}=4.099, \mathrm{p}<0.05\right)$. The analysis also showed that students who frequently 

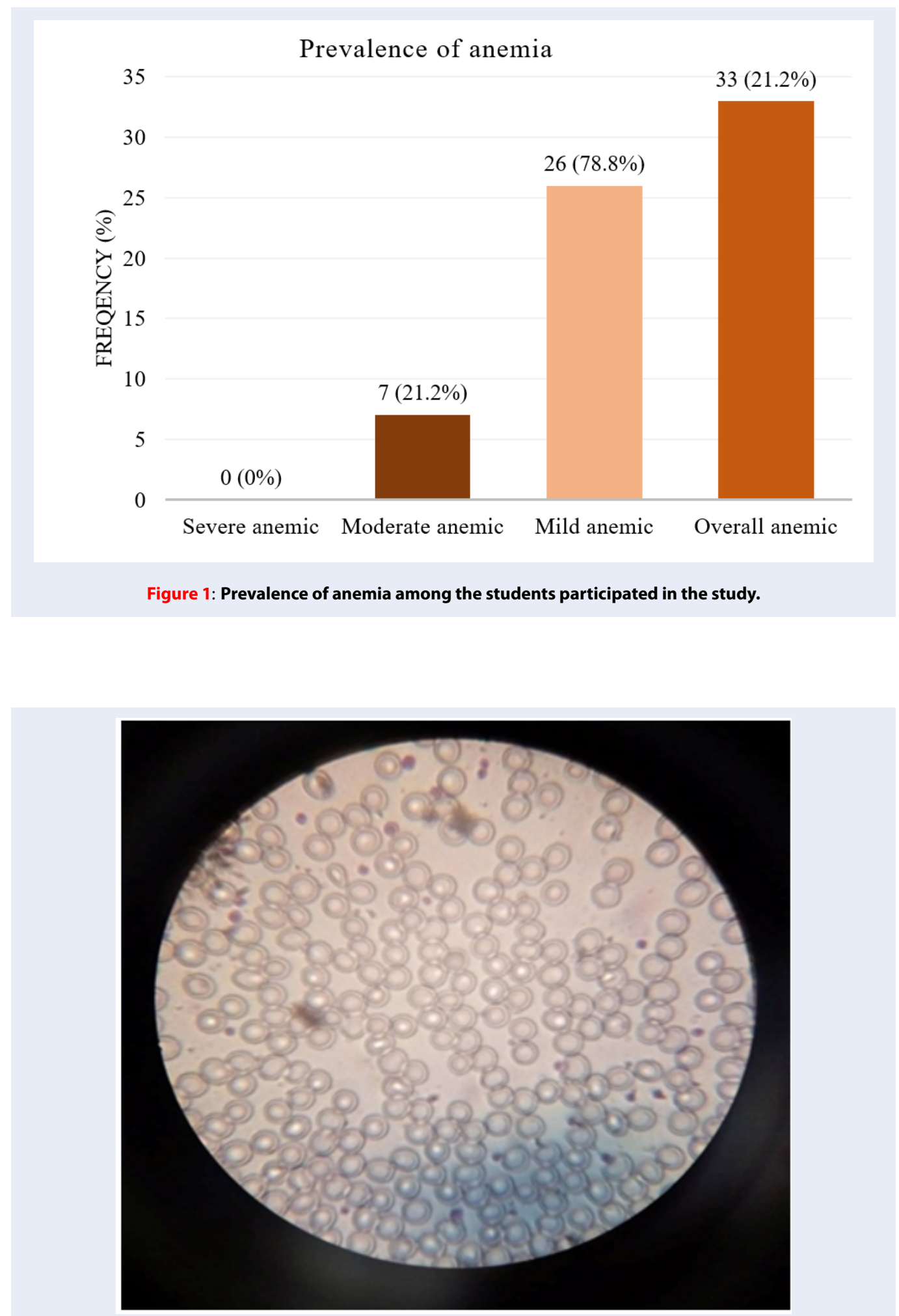

Figure 2: RBC morphological observation of the mild anemic students (Light Microscopic Examination), and the individual was diagnosed with normocytic normochromic anemia. 
Table 2: Distribution of anemia by characteristics of the students

\begin{tabular}{|c|c|c|c|c|}
\hline Characteristics & Total (\%) & Anemic (\%) & $\begin{array}{l}\chi^{2} \\
\text { value }\end{array}$ & p-value \\
\hline \multicolumn{5}{|l|}{ Age group (years) } \\
\hline $18-23$ & $130(86.7)$ & $28(21.5)$ & 0.121 & 0.73 \\
\hline $23+$ & $20(13.3)$ & $5(25.0)$ & & \\
\hline \multicolumn{5}{|l|}{ Gender } \\
\hline Male & $70(46.7)$ & $7(10.0)$ & 11.014 & $0.00^{*}$ \\
\hline Female & $80(53.3)$ & $26(32.5)$ & & \\
\hline \multicolumn{5}{|l|}{ Studying program } \\
\hline Biology & $50(33.3)$ & $9(18.0)$ & 0.605 & 0.44 \\
\hline Non-biology & $100(66.7)$ & $24(24.0)$ & & \\
\hline \multicolumn{5}{|l|}{ Studying year } \\
\hline $2^{\text {nd }}$ year & $22(14.7)$ & $8(36.4)$ & 5.414 & 0.07 \\
\hline $3^{\text {rd }}$ year & $97(64.7)$ & $22(22.7)$ & & \\
\hline $4^{\text {th }}$ year/Masters & $31(20.6)$ & $3(9.7)$ & & \\
\hline \multicolumn{5}{|l|}{ Relationship status } \\
\hline Single & 136(90.7) & $29(21.3)$ & 0.389 & 0.53 \\
\hline Married & $14(9.3)$ & $4(28.6)$ & & \\
\hline \multicolumn{5}{|c|}{ Family monthly income (BDT) } \\
\hline$\leq 10,000$ & $17(21.3)$ & $8(47.1)$ & 8.091 & $0.04^{*}$ \\
\hline $10,001-20,000$ & $61(40.7)$ & $11(18.0)$ & & \\
\hline $20,001-30,000$ & $32(21.3)$ & $8(25.0)$ & & \\
\hline$>30,000$ & $40(26.7)$ & $6(15.0)$ & & \\
\hline \multicolumn{5}{|c|}{ Presence of self-reported illness } \\
\hline Yes & $32(21.3)$ & $8(25.0)$ & 0.213 & 0.64 \\
\hline No & $118(78.7)$ & $25(21.2)$ & & \\
\hline \multicolumn{5}{|l|}{ Smoking habit } \\
\hline Yes & $31(20.7)$ & $9(29.0)$ & 1.126 & 0.29 \\
\hline No & $119(79.3)$ & $24(20.2)$ & & \\
\hline
\end{tabular}

${ }^{*} \mathrm{p}<0.05$ statistically significant

( $\geq 3$ times/week) consumed fruits, green leafy vegetables and animal products (meat, fish, egg) were less likely to be anemic $(\mathrm{p}<0.05)$ (Table 2$)$. In binary logistic regression analysis, daily breakfast intake (COR $=2.36,95 \% \mathrm{CI}=1.01-5.52 ; \mathrm{p}<0.05)$, frequently intake ( $\geq 3$ times/week) of fruits, green leafy vegetables, and animal products remained significant predictors of lower prevalence of anemia $(\mathrm{p}<0.05)$ (Table 4$)$.

\section{DISCUSSION}

Anemia is a common public health problem in developing countries. Anemia occurs at all ages ${ }^{19}$. However, there is a limited body of information on anemia among young adults. In the present study, we were able to determine the prevalence and its risk determinants of anemia among adult's students of Jahangirnagar University, Bangladesh. The study found the overall prevalence of anemia among university students 
Table 3: Distribution of anemia by hygiene practice and dietary intakes of the students

\begin{tabular}{|c|c|c|c|c|}
\hline Variable & Total (\%) & Anemic (\%) & $\chi 2$ value & $\mathrm{p}$-value \\
\hline \multicolumn{5}{|l|}{ Hygiene practice } \\
\hline \multicolumn{5}{|c|}{ Wash hand with soap before meal } \\
\hline Every time & $73(48.7)$ & $11(15.1)$ & 3.982 & $0.046^{*}$ \\
\hline Occasionally & $77(51.3)$ & $22(28.6)$ & & \\
\hline \multicolumn{5}{|c|}{ Wash hand with soap after using toilet } \\
\hline Every time & $115(76.7)$ & 20(17.4) & 6.101 & $0.014^{\star}$ \\
\hline Occasionally & $35(23.3)$ & $13(37.1)$ & & \\
\hline \multicolumn{5}{|l|}{ Brushing teeth per day } \\
\hline Once & $123(82.0)$ & $23(18.7)$ & 4.339 & $0.04^{*}$ \\
\hline Twice & $27(18.0)$ & $10(37.0)$ & & \\
\hline \multicolumn{5}{|l|}{ Cutting nails regulary } \\
\hline Yes & $114(76.0)$ & $21(18.4)$ & 3.546 & 0.06 \\
\hline No & $36(24.0)$ & $12(33.3)$ & & \\
\hline \multicolumn{5}{|l|}{ Dietary habits } \\
\hline \multicolumn{5}{|l|}{ Breakfast intake } \\
\hline Daily & $64(42.7)$ & $9(14.1)$ & 4.099 & $0.04^{*}$ \\
\hline Skip & $86(57.3)$ & $24(27.9)$ & & \\
\hline \multicolumn{5}{|l|}{ Fruits intake } \\
\hline Frequently ( $\geq 3$ times/week) & $47(31.3)$ & $9(19.1)$ & 9.385 & $0.00^{*}$ \\
\hline Infrequently (<3times/week) & $85(56.7)$ & 15(17.6) & & \\
\hline Occasionally & $18(12.0)$ & $9(50.0)$ & & \\
\hline \multicolumn{5}{|l|}{ Green leafy vegetables intake } \\
\hline Frequently ( $\geq 3$ times/week) & $84(56.0)$ & $11(13.1)$ & 8.822 & $0.01^{*}$ \\
\hline Infrequently (<3times/week) & $54(36.0)$ & $18(33.3)$ & & \\
\hline Occasionally & $12(8.0)$ & $4(33.3)$ & & \\
\hline \multicolumn{5}{|l|}{ Milk/dairy products intake } \\
\hline Frequently ( $\geq 3$ times/week) & 107(71.3) & $19(17.8)$ & 4.243 & 0.11 \\
\hline Infrequently (<3times/week) & $35(23.3)$ & $12(34.3)$ & & \\
\hline Occasionally & $8(5.3)$ & $2(25.0)$ & & \\
\hline \multicolumn{5}{|c|}{ Animal products (meat, fish, egg) intake } \\
\hline Frequently ( $\geq 3$ times/week) & $95(63.3)$ & $12(12.6)$ & 13.882 & $0.00^{*}$ \\
\hline Infrequently (<3times/week) & $42(28.0)$ & $15(35.7)$ & & \\
\hline Occasionally & $13(8.7)$ & $6(46.2)$ & & \\
\hline
\end{tabular}

${ }^{*} \mathrm{p}<0.05$ statistically significant 
Table 4: Regression analysis of factors associated with anemia among the students

\begin{tabular}{|c|c|c|c|c|}
\hline Variables & COR $(95 \% \mathrm{CI})$ & p-value & $\operatorname{AOR}(95 \% \mathrm{CI})$ & $\mathrm{p}$-value \\
\hline \multicolumn{5}{|l|}{ Hygiene practice } \\
\hline \multicolumn{5}{|c|}{ Wash hand with soap before meal } \\
\hline Every time & Reference & $0.05^{\star}$ & Reference & $0.04^{*}$ \\
\hline Occasionally & $2.25(1.00-5.07)$ & & $2.17(1.1-5.09)$ & \\
\hline \multicolumn{5}{|c|}{ Wash hand with soap after using toilet } \\
\hline Every time & Reference & $0.02^{*}$ & Reference & $0.01^{*}$ \\
\hline Occasionally & $2.81(1.21-6.49)$ & & $2.79(1.21-6.48)$ & \\
\hline \multicolumn{5}{|l|}{ Brushing teeth per day } \\
\hline Once & Reference & 0.06 & Reference & 0.06 \\
\hline Twice & $2.21(0.96-5.13)$ & & $2.17(0.96-5.09)$ & \\
\hline \multicolumn{5}{|l|}{ Cut nails regulary } \\
\hline Yes & Reference & $0.04^{*}$ & Reference & $0.04^{*}$ \\
\hline No & $2.56(1.04-6.31)$ & & $2.51(1.01-5.91)$ & \\
\hline \multicolumn{5}{|l|}{ Dietary habits } \\
\hline \multicolumn{5}{|l|}{ Breakfast intake } \\
\hline Daily & Reference & $0.05^{\star}$ & Reference & $0.04^{*}$ \\
\hline Skip & $2.36(1.01-5.52)$ & & $2.33(1.03-5.51)$ & \\
\hline \multicolumn{5}{|l|}{ Fruits intake } \\
\hline Frequently ( $\geq 3$ times/week) & Reference & & Reference & \\
\hline Infrequently (<3times/week) & $4.22(1.3-13.68)$ & $0.02^{\star}$ & $4.21(1.3-13.65)$ & $0.01^{*}$ \\
\hline Occasionally & $4.67(1.59-13.73)$ & $0.05^{*}$ & $4.65(1.58-13.72)$ & $0.01^{*}$ \\
\hline \multicolumn{5}{|l|}{ Green leafy vegetables intake } \\
\hline Frequently ( $\geq 3$ times/week) & Reference & & Reference & \\
\hline Infrequently (<3times/week) & $3.32(0.86-12.9)$ & 0.08 & $3.29(0.85-11.7)$ & 0.08 \\
\hline Occasionally & $1.0(0.27-3.77)$ & 1.00 & $0.9(0.25-3.57)$ & 0.91 \\
\hline \multicolumn{5}{|l|}{ Milk/dairy products intake } \\
\hline Frequently ( $\geq 3$ times/week) & Reference & & Reference & \\
\hline Infrequently (<3times/week) & $1.54(0.29-8.25)$ & 0.61 & $1.51(0.27-8.21)$ & 0.60 \\
\hline Occasionally & $0.64(0.11-3.66)$ & 0.62 & $0.62(0.09-3.47)$ & 0.61 \\
\hline \multicolumn{5}{|c|}{ Animal products (meat, fish, egg) intake } \\
\hline Frequently ( $\geq 3$ times/week) & Reference & & Reference & \\
\hline Infrequently (<3times/week) & $5.93(1.7-20.63)$ & $0.01^{\star}$ & $5.12(1.6-19.76)$ & $0.01^{\star}$ \\
\hline Occasionally & $1.54(0.44-5.44)$ & 0.50 & $1.49(0.43-5.39)$ & 0.52 \\
\hline
\end{tabular}

${ }^{*} \mathrm{p}<0.05$ statistically significant 


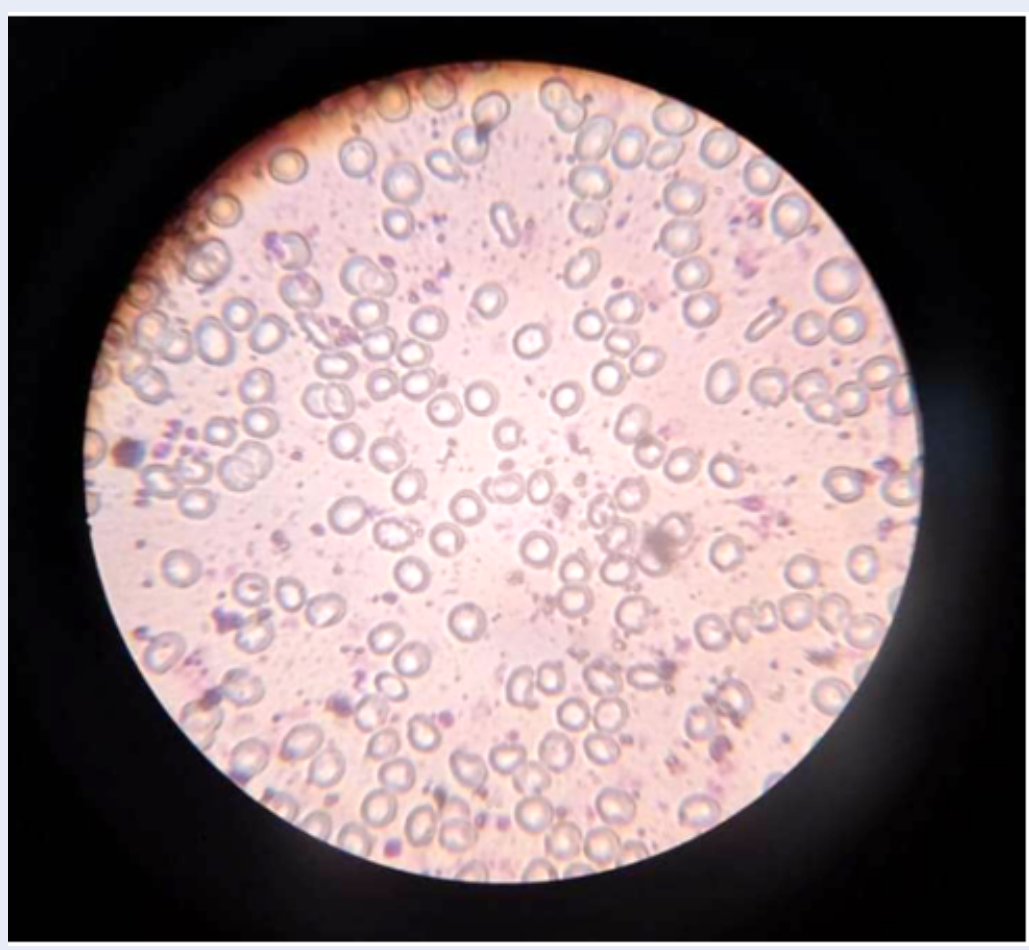

Figure 3: RBC morphological observation of the moderate anemic students (Light Microscopic Examination), and the individual was diagnosed with microcytic hypochromicanemia.

$22.0 \%(\mathrm{n}=33)$, of whom $78.8 \%(\mathrm{n}=26)$ were females and $21.2 \%(n=7)$ were males. However, the present study showed a lower prevalence of anemia than a similar study that was conducted among university students of the Noakhali Region, Bangladesh, which reported it to be $55.3 \%{ }^{7}$. The possible reason for the lower prevalence of anemia in the current study might be differences in the study period. Bangladesh Govt. along with national and international NGOs has delivered health education through mass me$\mathrm{dia} /$ print media and tried to promote healthy behaviors among the general population. Students might be exposed to these interventions which in turn, influences the prevalence of anemia in the present study. As in Bangladesh, university students of other countries were also affected by anemia reported by several studies. The anemia prevalence rate was reported to be $30.2 \%$ among medical students in India ${ }^{20}$. A similar study in Saudi Arabia revealed that anemia was prevalent in $64 \%$ of female students of University $^{21}$. In the present study, the prevalence of mild anemia among the students was higher than moderate anemia and there was no student having severe anemia. This finding is consistent with other studies $^{21,22}$. In the present study, we also found that mild anemic students had normocytic ormochromic anemia while moderate anemic students had microcytic hypochromic anemia. The causes of normocytic normochromic anemia are either increased red blood cell destruction or decreased red blood cell production and overexpansion of plasma volume ${ }^{23}$. Microcytic hypochromic anemia usually results from iron deficiency $^{24}$. The findings of the study showed that female students were more likely to be anemic compared to males. Previous studies reported similar findings that females are at more risk to develop anemia than males ${ }^{6,7}$. Females are prone to anemia because of menstruation. An estimated $42 \mathrm{mg}$ of iron losses per menstrual cycle in females with heavy blood flow, which may lead to anemia ${ }^{25}$. Other possible reasons might be illiteracy, poor dietary habits, and sanitation $^{7,26}$. The study showed that monthly family income had an effect on anemia. This finding is consistent with previous studies ${ }^{27,28}$. Low household income badly affects an individual's food purchasing capacity. In addition, people living in poor households are found with inadequate dietary intakes and a high risk of nutritional deficiencies ${ }^{29,30}$. Good hygiene practice is an important measure to prevent anemia $^{26}$. In this study, good hygiene practice i.e., handwashing with soap before the meal and after using the 
toilet and cutting nails regularly is significantly associated with a lower prevalence of anemia. This finding agrees with previous studies ${ }^{26,29}$. Poor hygiene practice favors parasite infections ${ }^{26}$. Parasites cause blood loss which may lead to direct anemia ${ }^{31}$. Inadequate dietary intake plays an important role in the causation of anemia. The findings of the study revealed that the students who skipped breakfast were at increased risk to develop anemia than others. Missing meal means cutting calories which in turn cause weight loss and may lead to anemia. University students might miss breakfast meals due to waking up late, not being hungry in the morning, or dislike of served food. The study also revealed that the students who frequently consumed fruits and green leafy vegetables ( $\geq 3$ times/week) were less likely to be anemic than others. Previous studies on Bengali students and Saudi women have demonstrated that low consumption of fruits and vegetables is associated with anemia $^{7,31}$. While the etiology of anemia is multifactorial, it is primarily caused by the deficiency of micronutrients (e.g., vitamins A, B12 or folate) and minerals (commonly iron) ${ }^{9,32}$. Fruits and vegetables are good sources of vitamins and minerals and adequate consumption of fruits and vegetables promotes $\mathrm{Hb}$ level in the individuals. The study also revealed that the students who frequently consumed animal products (meat, fish, and eggs) had a lower prevalence of anemia. Animal products such as meat, fish, and egg are generally enriched in iron ${ }^{11}$ and these types of foods enhance the iron status, as the form of iron in animal products absorbs more easily than the iron in vegetables ${ }^{9}$. However, we did not find any association between the intake of milk/dairy products and anemia. This may possibly because of the small sample size.

\section{CONCLUSION}

The proportion of anemia was found to be significantly higher in females. Further study with a large sample is needed to validate the findings as well as to safeguard the health of these future mothers. Proper health education to increase knowledge about anemia, benefits of healthy dietary habits and the importance of hygiene practice can be implemented among the students.

\section{LIMITATIONS}

The present study had several limitations. Lack of adequate funding was a major problem in this study. Due to limited funding and resources, other hematological parameters, except $\mathrm{Hb}$, such as hematocrit, red blood cell count, serum ferritin, etc. were not estimated. In addition, the dietary habit was based on self-reported data, thus recall bias could be problematic. The study was confined to a single university and included a limited sample size. So, the results might not be generalized.

\section{ABBREVIATIONS}

Hb: Hemoglobin

GDP: Gross Domestic Products

WHO: World Health Organization

COR: Crude Odds Ratio

AOR: Adjusted Odds Ratio

CI: Confidence Interval

RBC: Red Blood Cell

\section{CONFLICT OF INTEREST}

No conflict of interest.

\section{CONTRIBUTORS}

Mst. Sabrina Moonajilin conceived and planned the experiments. Quazi Maksudur Rahman and Abid Hasan Khan carried out the experiments. Mst. Sabrina Moonajilin and Md. Estiar Rahman planned and carried out the simulations. Mst. Sabrina Moonajilin, Md. Estiar Rahman, Quazi Maksudur Rahman and Abid Hasan Khan contributed to the interpretation of the results. Md. Estiar Rahman took the lead in writing the manuscript. All authors provided critical feedback and helped shape the research, analysis, and manuscript.

\section{ACKNOWLEDGEMENT}

The study conducted with partial support from Jahangirnagar University. The authors would like to thank all the students who voluntarily participate in the study.

\section{REFERENCES}

1. World Health Organization. Haemoglobin Concentrations for the Diagnosis of Anaemia and Assessment of Severity. Miner Nutr Inf Syst World Heal Organ. 2013;p. 1-6. Available from: 2011.

2. Hay SI, Vos T, Abajobir AA, et al. Global, regional, and national incidence, prevalence, and years lived with disability for 328 diseases and injuries for 195 countries, 1990-2016: a systematic analysis for the Global Burden of Disease Study 2016. Lancet. 2017;390(10100):1211-1259. Available from: https://doi.org/10.1016/S0140-6736(17)32130-X.

3. Habibzadeh F, Farrokh. Anemia in the Middle East. Lancet. 2012;379:1.

4. Patel KV. Epidemiology of Anemia in Older Adults. Semin Hematol. 2008;45(4):210-217. PMID: 18809090. Available from: doi:10.1053/j.seminhematol.2008.06.006https://doi.org/ 10.1053/j.seminhematol.2008.06.006.

5. Rakic L, Djokic D, Drakulovic MB, Pejic A, Radojicic Z, Marinkovic M. Risk factors associated with anemia among Serbian non-pregnant women 20 to 49 years old. A crosssectional study. Hippokratia. 2013;17(1):47-54. 
6. Rani NA, Arasegowda R, Mukherjee P, Dhananjay SY. Prevalence of nutritional deficiency anaemia and its impact on scholastic performance among undergraduate medical students. J Clin Diagnostic Res. 2017;11(3). PMID: 28511373. Available from: doi:10.7860/JCDR/2017/25367.9597.

7. Shill K, Karmakar P, Kibria M, et al. Prevalence of irondeficiency anaemia among university students in Noakhali region, Bangladesh. J Health Popul Nutr. 2014;32(1):103-110.

8. Al-Alimi, Ahmed A, Bashanfer S, Morish MA. Prevalence of Iron Deficiency Anemia among University Students in Hodeida Province, Yemen. Anemia 2018. 2018;PMID: 29850236. Available from: doi:10.1155/2018/4157876https://doi.org/10.1155/ 2018/4157876

9. Beck KL, Conlon CA, Kruger R, Coad J. Dietary determinants of and possible solutions to iron deficiency for young women living in industrialized countries: A review. Nutrients. 2014;6(9):3747-3776. PMID: 25244367. Available from https://doi.org/10.3390/nu6093747.

10. Haas JD, Brownlie T. Iron deficiency and reduced work capacity: a critical review of the research to determine a causal relationship. J Nutr. 2001;131(2S-2):676S-690S. PMID: 11160598. Available from: doi:10.1093/jn/131.2.676S.

11. Kader A. Importance of Fruits, Nuts, and Vegetables in Human Nutrition and Health. Perishables HandI Q. 2001;106:106. Available from: https://doi.org/10.1300/J501v28n01_02.

12. Péneau S, Dauchet $L$, Vergnaud AC, et al. Relationship between iron status and dietary fruit and vegetables based on their vitamin C and fiber content. Am J Clin Nutr. 2008;87(5):1298-1305. PMID: 18469253. Available from: https://doi.org/10.1093/ajcn/87.5.1298.

13. Gan WY, Nasir MTM, Zalilah MS, Hazizi AS. Differences in eating behaviours, dietary intake and body weight status between male and female Malaysian university students. Malays J Nutr. 2011;17(2):213-228.

14. Sanou D, Turgeon-O'Brien H, Desrosiers T. Nutrition intervention and adequate hygiene practices to improve iron status of vulnerable preschool Burkinabe children. Nutrition. 2010;26(1):68-74. PMID: 19628372. Available from: https: //doi.org/10.1016/j.nut.2009.05.017.

15. Bangladesh Continues to Reduce Poverty But at Slower Pace;

16. DHS. Bangladesh DHS 2014 - Preliminary Report. 2014;.

17. Khan JR, Awan N, Misu F. Determinants of anemia among 6-59 months aged children in Bangladesh: Evidence from nationally representative data. BMC Pediatr. 2016;16(1):1-12. PMID: 26754288. Available from: https://doi.org/10.1186/s12887015-0536-z.

18. Nutritional anaemias. Report of a WHO scientific group. World Health Organ Tech Rep Ser. 1968;405:5-37.

19. Llanos MJG, Zamudio JLG, Reyes-García LMJL. Significance of anaemia in the different stages of life. Enferm Glob. 2016;15(3):407-430. Available from: https://doi.org/10.6018/ eglobal.15.3.248221.
20. Pandey AS. A Cross Sectional Study of Nutritional Anemia among Medical Students in a Medical College, at Bilaspur, Chhattisgarh. Natl J Med Res. 2013;3(2):143-146.

21. Hassand NA. The prevalence of iron deficiency anemia in a Saudi University female students. J Microsc Ultrastruct. 2014;3(1):25. PMID: 30023178. Available from: https://doi.org/ 10.1016/j.jmau.2014.11.003.

22. Abalkhail B, Shawky S. Prevalence of daily breakfast intake, iron deficiency anaemia and awareness of being anaemic among Saudi school students. Int J Food Sci Nutr. 2002;53(6):519-528. PMID: 12590747. Available from: https: //doi.org/10.1080/09637480220164370.

23. Normocytic Anemia. Available from: https://www.aafp.org/ afp/2000/1115/p2264.html.

24. Meredith JL, Rosenthal NS. Differential diagnosis of microcytic anemias. Lab Med. 1999;30(8):538-542. Available from: https: //doi.org/10.1093/labmed/30.8.538.

25. Rowland T. Iron Deficiency in Athletes. Am J Lifestyle Med 2012;6(4):319-327. Available from: https://doi.org/10.1177/ 1559827611431541 .

26. Coffey D, Geruso M. Sanitation, Disease, and Anemia: Evidence From Nepal. Econ J. 2015;p. 1-37. PMID: 29937551 Available from: https://doi.org/10.1111/ecoj.12491.

27. Ahmed S, Mamun AA, Mahmud N, et al. Prevalence and Associated Factors of Anemia among Pregnant Women Receiving Antenatal Care ( ANC) at Fatima Hospital in Jashore , Bangladesh : A Cross-Sectional Study. 2019;43:1056-1071. Available from: https://doi.org/10.4236/fns.2019.109076.

28. Kejo D, Petrucka P, Martin H, Kimanya M, Mosha T. Prevalence and predictors of anemia among children under 5 years of age in Arusha District, Tanzania. Pediatr Heal Med Ther. 2018;9:915. PMID: 29443328. Available from: https://doi.org/10.2147/ PHMT.S148515.

29. Siva PM, Sobha A, Manjula VD. Prevalence of anaemia and its associated risk factors among adolescent girls of central Kerala. J Clin Diagnostic Res. 2016;;10(11):LC19-LC23. PMID: 28050409. Available from: https://doi.org/10.7860/JCDR/ 2016/20939.8938.

30. Stephen G, Mgongo M, Hashim TH, Katanga J, Stray-Pedersen B, Msuya SE. Anaemia in Pregnancy: Prevalence, Risk Factors, and Adverse Perinatal Outcomes in Northern Tanzania. Anemia. 2018;2018:1-9. PMID: 29854446. Available from: https://doi.org/10.1155/2018/1846280.

31. Farid Z, N V, Patwardhan PWJDN. Parasitism and Anemia. Am J Clin Nutr. 1969;22(5):498-503. PMID: 5778077. Available from: https://doi.org/10.1093/ajcn/22.4.498.

32. Righetti AA, Koua AYG, Adiossan LG, et al. Etiology of anemia among infants, school-aged children, and young nonpregnant women in different settings of South-Central Côte d'Ivoire. Am J Trop Med Hyg. 2012;87(3):425-434. PMID: 22848097. Available from: https://doi.org/10.4269/ajtmh.2012. 11-0788. 